\title{
RHOMBUS AND RHOMBOID PARALLELOGRAM PATTERNS ON GLACIERS: NATURAL INDIGATORS OF STRAIN
}

\author{
By Charles J. WaAG \\ (Department of Geology, Georgia State University, University Plaza, Atlanta, Georgia 30303, \\ U.S.A., and Foundation for Glacier and Environmental Research, Seattle, Washington 98 rog, \\ U.S.A.)
}

\section{and Keith Echelmeyer}

(Division of Geological and Planetary Science, California Institute of Technology, Pasadena, California 9 I 1 25, U.S.A., and Juneau Icefield Research Program, Seattle, Washington 981 og, U.S.A.)

ABstract. Subtle rhombus and rhomboid parallelogram patterns occur on Vaughan Lewis Glacier and the Gilkey Glacier System, Juneau Icefield, Alaska. The patterns are within the firn at the firn-ice interface, are formed by differential recrystallization within narrow preferred zones, and are apparently manifestations of stresses transferred upward from the glacier ice. On the glaciers of the Gilkey System the patterns occur where intense lateral shortening is indicated by abrupt convergence of medial moraines and an abundance of extension crevasses. The short axes of the rhombi and the obtuse angle bisectors of the rhomboids are subparallel to the strike of extension crevasses, therefore to the axis of shortening. The long axes of the rhombi and the acute angle bisectors of the rhomboids are parallel to the foliation, and ice-flow direction. The angles of the parallelograms are variable locally, but average $105^{\circ}$ and $75^{\circ}$; the variation seems to reflect intensity and duration of stress. Similar parallelograms occur within the troughs of wave bulges below the Vaughan Lewis Icefall. In the wave bulges, the foliation arcs parallel the wave. The long axes of the rhombi and acute angle bisectors of the rhomboids parallel the foliation around the foliation arc. The short axes of the rhombi and the obtuse angle bisectors of the rhomboids parallel the strikes of radial crevasses, are perpendicular to the direction of extension, and form a fan divergent down-stream. The precise mechanisms and conditions of formation of the parallelograms are not yet understood. Preliminary strainrate measurements suggest, however, that correlations exist between the orientations of the principal strainrates and the axes of the patterns, and between the magnitude of the strain-rates and the axial lengths of the
patterns.

RÉsumé. Formation de losanges et de parallelogrammes rhomboïdaux dans les glaciers: un indicateur naturel des contraintes. Des formations fines de losanges et de parallelogrammes rhomboïdaux se produisent sur le Vaughan Lewis Glacier et sur le Gilkey Glacier System, dans le Juneau Icefield, Alaska. Ces formations se situent dans le névé à l'interface entre le névé et la glace, elles proviennent de la recristallisation différentielle dans d'étroites zones favorables et sont apparemment des manifestations d'efforts transmis vers le haut en provenance de la glace de glacier. Sur les glaciers du Gilkey System ces formations prennent place aux endroits où un intense rétrécissement est relevé par la convergence soudaine des moraines médianes et une abondance des crevasses d'extension. Les petits axes des losanges et les bisecteurs des angles obtus des rhomboïdes sont à peu près parallèles à la direction des crevasses d'extension, donc à l'axe du rétrécissement. Le grand axe des losanges et les bissecteurs des angles aigus des rhomboïdes sont parallèles à la foliation et à la direction de l'écoulement de la glace. Les angles des parallélogrammes sont localement variables mais valent en moyenne $105^{\circ}$ et $75^{\circ}$; les variations semblent refléter l'intensité et la durée de l'effort. Des parallélogrammes semblables se produisent dans les creux des ondulations superficielles sous les séracs du Vaughan Lewis. Dans les ondulations, les arcs des foliations sont parallèles aux ondulations. Les grands axes des losanges et les bissecteurs des angles aigus des rhomboïdes sont parallèles à la foliation le long des arcs de foliation. Les petits axes des losanges et les bissecteurs des angles obtus des rhomboïdes sont parallèles à la direction des crevasses radiales, ils sont perpendiculaires à la direction de l'extension et forment un éventail divergent vers l'aval. On ne comprend pas encore les mécanismes précis et les conditions de formation des parallélogrammes. Des mesures préliminaires de vitesse de déformation suggèrent néanmoins qu'il existe des corrélations entre les orientations des contraintes et les axes des formations et entre l'ordre de grandeur de ces contraintes et la longueur des axes de ces formations.

Zusammenfassung. Rhombische und rhomboidische Parallelogram-Muster auf Gletschern als natürliche Anzeichen für Spannung. Feine rhombische und rhomboidische Parallelogram-Muster treten auf dem Vaughan Lewis Glacier und dem Gilkey Glacier-System des Juneau Icefield in Alaska auf. Die Muster liegen im Firngebiet und an der Grenze zwischen Firn und Eis, entstehen durch differentielle Rekristallisation innerhalb eng begrenzter Zonen und sind offensichtlich Auswirkungen von Spannungen, die aus dem Gletschereis nach oben übertragen werden. Auf den Gletschern des Gilkey-Systems treten die Muster dort auf, wo intensives seitliches Schrumpfen durch plötzliches Zusammenlaufen von Mittelmoränen und eine grosse Zahl von Zugspalten angezeigt wird. Die kurzen Diagonalen der Rhomben und die Halbierenden der stumpfen Winkel der Rhomboiden sind parallel zur Richtung der Zugspalten, und damit zur Schrumpfungsachse. Die langen Diagonalen der Rhomben und die Winkelhalbierenden der spitzen Winkel der Rhomboide sind 
parallel zur Bänderung und zur Richtung des Eisflusses. Die Winkel der Parallelogramme sind lokal verschieden, betragen im Mittel jedoch $105^{\circ}$ und $75^{\circ}$; die Schwankungen scheinen die Intensität und Dauer der Spannung widerzuspiegeln. Ähnliche Parallelogramme treten innerhalb der Tröge von Aufwölbungen unter dem Vaughan Lewis-Eisfall auf. Auf den Wölbungen verläuft die Bänderung parallel zu den Kämmen. Die langen Diagonalen der Rhomben und die Winkelhalbierenden der spitzen Winkel der Rhomboide sind parallel zur Bänderung. Die kurzen Diagonalen der Rhomben und die Winkelhalbierenden der stumpfen Winkel der Rhomboide sind parallel zum Verlauf der Radialspalten und damit senkrecht zur Ausdehnungsrichtung; sie bilden einen stromab geöffneten Fächer. Mechanismus und Voraussetzung der Bildung der Parallelogramme sind noch nicht genau bekannt. Doch deuten vorläufige Deformationsmessungen darauf hin, dass Korrelationen zwischen der Orientierung der Spannungshauptachsen und der Diagonalen der Muster, sowie zwischen der Grösse der Verformungsrate und der Diagonalenlänge der Muster bestehen.

\section{IXIR()) (TION}

Subtle rhombus and rhomboid parallelogram patterns have been noted on Vaughan Lewis Glacier and the glaciers of the Gilkey System, Juneau Icefield, Alaska. In late summer as the firn-pack ablates to a thin veneer, faint rhombus and rhomboid parallelogram patterns appear in the lowermost centimeter of firn at the firn-glacier-ice interface (Fig. I). In plan the parallelograms range from a few centimeters to greater than a meter on a side, and are manifestations of differential recrystallization within narrow preferred zones less than $\mathrm{I} \mathrm{cm}$ to several centimeters in width. Firn crystals within these narrow zones of recrystallization are coarser grained and average approximately $5 \mathrm{~mm}$ in diameter, whereas those within the parallelogram outlined by the zones average only $2.5 \mathrm{~mm}$. The orientation of the patterns in the third dimension is difficult to determine; however, they appear to project vertically downward through the firn only as far as the glacier-ice contact. Thus, although the patterns have been observed during portions of two field seasons they are ephemeral and disappear as the thin veneer of firn ablates.
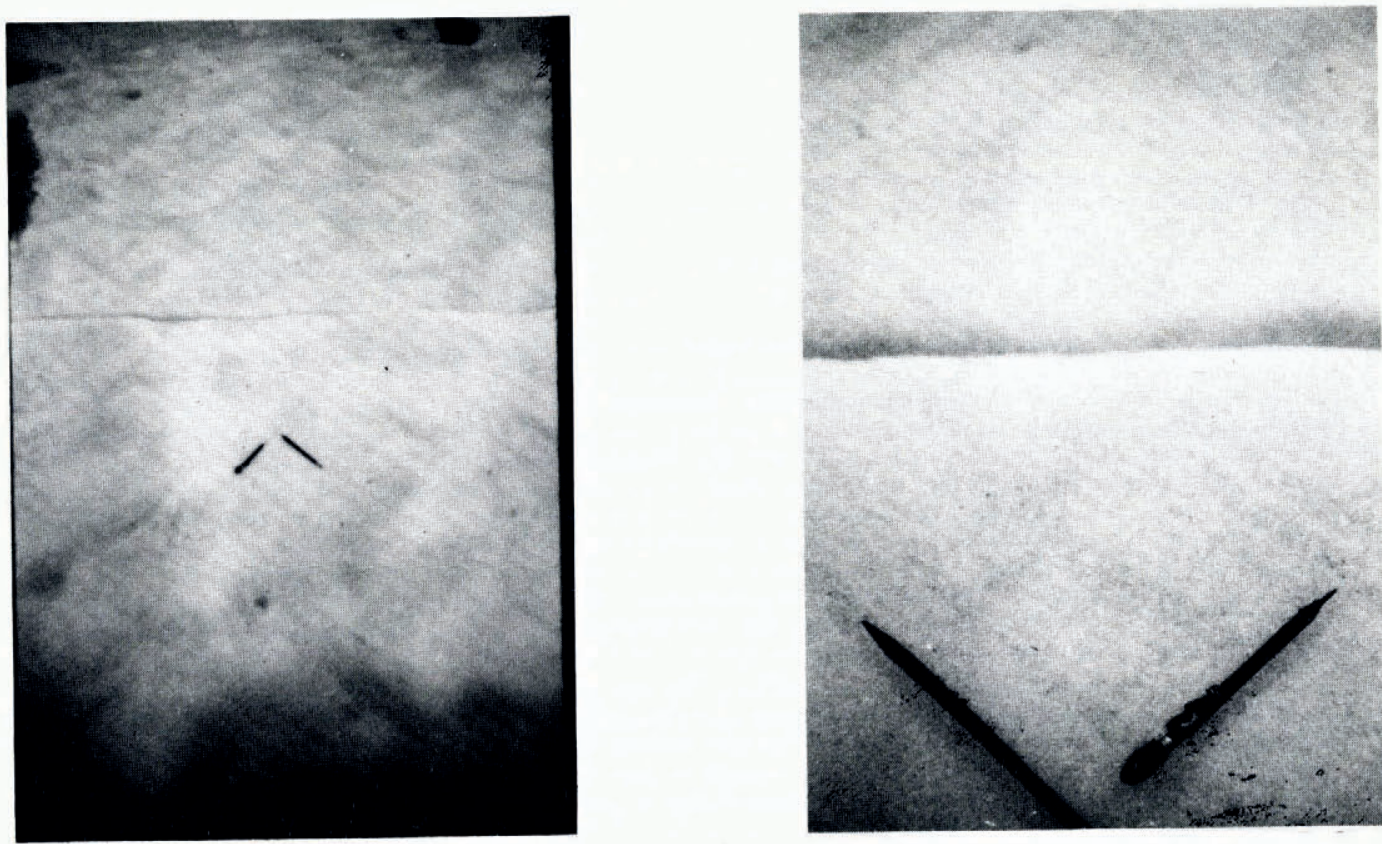

Fig. I. Photographs of rhombus and rhomboid parallelogram patterns in basal firn. Zones of more coarsely crystalline firn outlining lighter, less coarsely crystalline parallelograms. Note crevasses approximately parallel to the short axes of rhombi and obtuse-angle bisectors of rhomboids. 
To date, the parallelogram patterns have been observed only in areas in which the underlying glacial ice is thought to be under relatively great stress. On the glaciers of the Gilkey System where the patterns have been noted, large amounts of shortening are indicated by rather abrupt convergence of medial moraines immediately beneath a right-angle bend (Fig. 2). Patterns observed on Vaughan Lewis Glacier occurred in the compressional zone of wave bulges immediately beneath Vaughan Lewis Icefall.

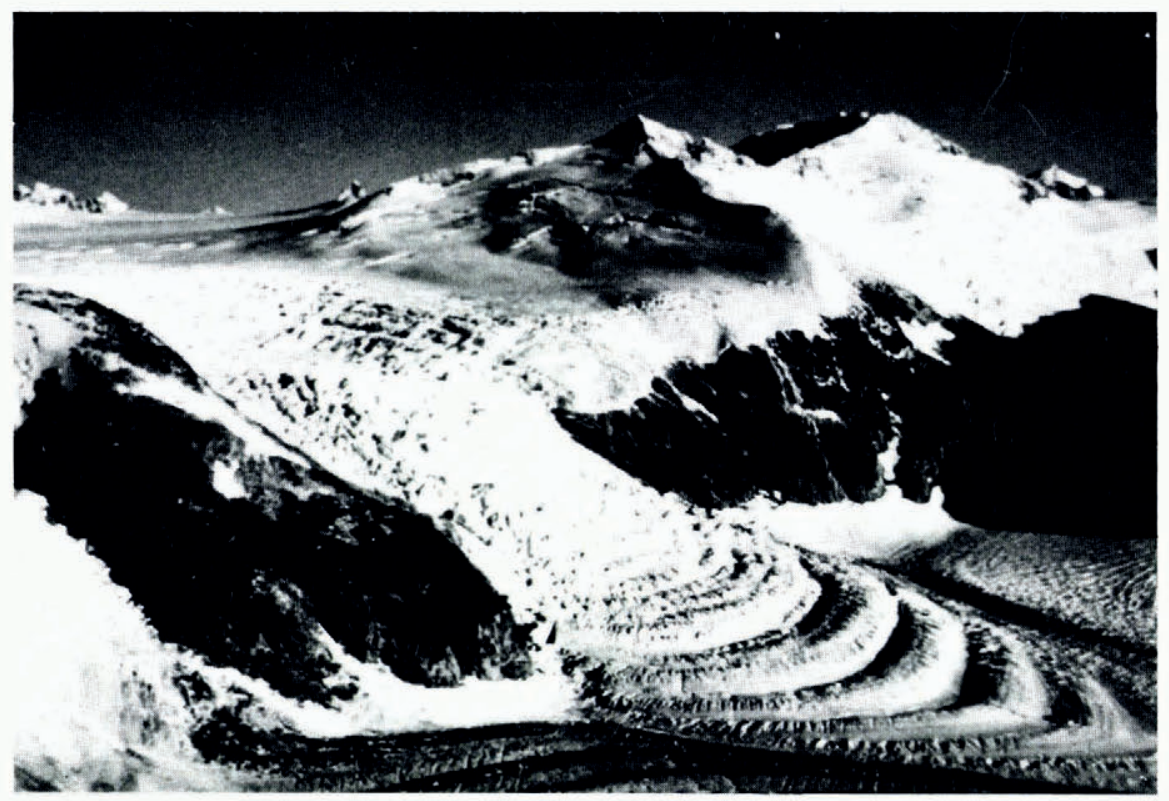

Fig. 2. Photograph of Vaughan Lewis Icefall and glaciers of the Gilkey System. Parallelogram patterns occur in the troughs of the wave bulges and between the converging moraines just below bend in foreground.

The precise mechanisms and conditions of formation of the patterns are not as yet understood; however, the parallelograms are consistently oriented relative to the stress orientations as interpreted from the physical setting and the structures within the underlying glacial ice. This consistent relationship prompts the interpretation that the parallelograms are natural strain indicators of stresses within the glacial ice. The strain is thought to be transmitted upward through the ice and manifested in patterns in the firn just above the firn-ice contact. The patterns do not appear to extend below the firn-ice contact. Whether or not they do, however, cannot be stated with certainty at this point in the study. It may be that the patterns are present in the underlying glacial ice, but they have not been detected because of the masking effect of other structures within the ice.

The writers have been unable to find such patterns in firn or ice described in the literature, however, it seems unlikely that they are unique to the glaciers of the Juneau Icefield. In fact, Echelmeyer observed and photographed similar patterns on Blue Glacier, Washington during the 1977 field season. The geometry of the patterns is curiously similar to quadramodal plots of $c$-axis orientations of ice crystals in some ice petrographic studies (Kamb, I959, fig. 3; Rigsby, I95I, fig. 4).

Since the parallelogram patterns on the Juneau Icefield have been found only in what seem to be high-stress environments, the physical setting and the structures within the ice in areas in which they occur deserve detailed description. 


\section{Physical setting}

Vaughan Lewis Glacier and the glaciers of the Gilkey System have their origins in the high ice and firn plateau of the Juneau Icefield. The glaciers of the Gitkey System flow off the high plateaus in the vicinity of Mount Ogilvie ( $2367.6 \mathrm{~m}$ ) and cascade into a broad, deep, glaciated valley referred to as the Gilkey Trench (Fig. 3). In its upper portion the trench with its complex of glaciers trends southward, then makes an abrupt right-angle turn westward toward Berners Bay on the Alaskan Coast. Vaughan Lewis Glacier enters the trench at the point where the glaciers of the Gilkey System swing through the right-angle bend in the trench. At this juncture, firn and glacial ice cascade approximately $515 \mathrm{~m}$ down the trench wall forming the spectacular Vaughan Lewis Icefall.

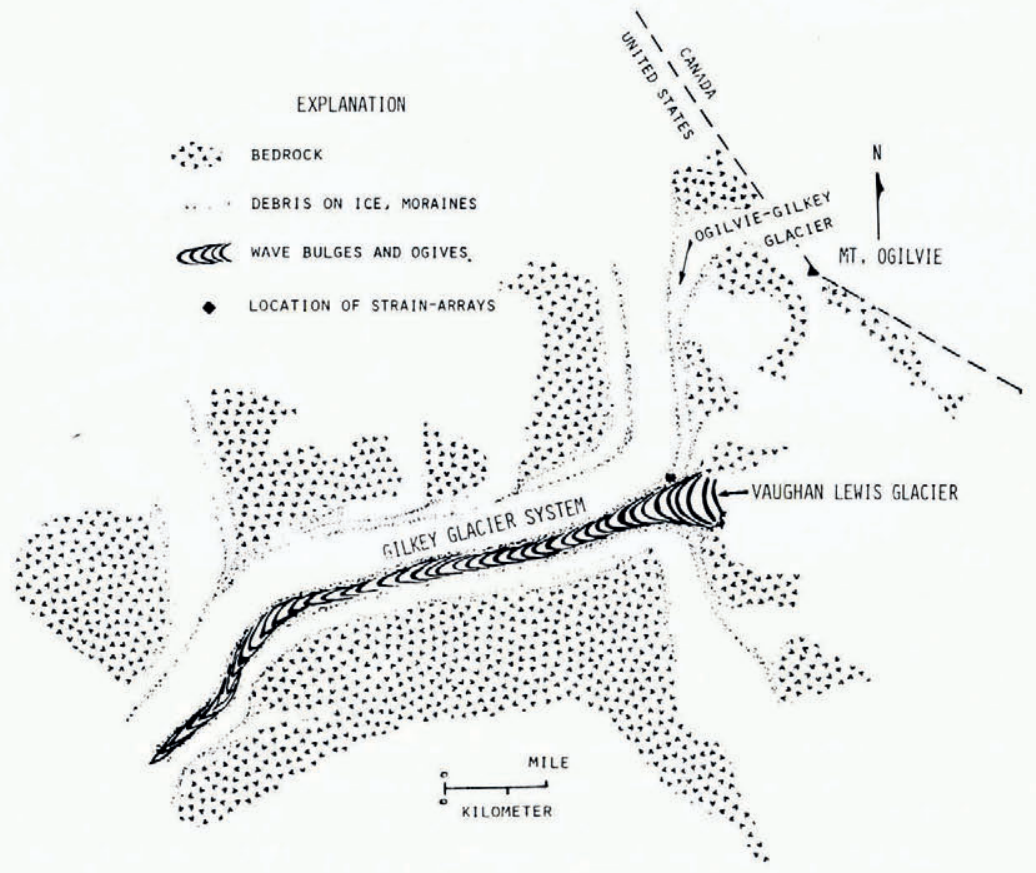

Fig. 3. Location map showing position of strain-arrays on Ogilvie-Gilkey Glacier of the Gilkey Glacier System.

Large quantities of ice and firn are contributed to the trench by the Vaughan Lewis, and wave-bulges or wave-ogives $30 \mathrm{~m}$ in height and $125 \mathrm{~m}$ in wavelength are generated at the base of the fall. (Wavelength here indicates the maximum map distance between adjacent wave crests or troughs, and height indicates the difference in elevation between adjacent wave crests and troughs.)

Crowding induced by the massive accumulation of Vaughan Lewis ice in the wave bulges, and the effects of the swing in the flow of Gilkey ice contributes to a rapid decrease in the width of the glaciers of the Gilkey Complex. Convergence of the lateral moraines of Ogilvie-Gilkey Glacier, one of the glaciers of the Gilkey System, indicates a lateral shortening of $33 \%$ in a flow distance of $100 \mathrm{~m}$. The greatest abundance of parallelogram patterns found in the trench has occurred in this high-stress zone. 


\section{ENGLACIAL STRUGTURES AND INTERPRETATION OF THE PRINCIPAL STRESS DIRECTIONS}

The glacial ice beneath the firn in which the patterns develop does not appear to be significantly different from that elsewhere in the glaciers. Relatively clear, coarsely crystalline, well-foliated ice is most abundant; however, intercalations of finer-grained, poorly foliated white bubbly ice are common.

Above the right-angle bend in Ogilvie-Gilkey Glacier, the foliation strikes subparallel to the longitudinal axis of the glacier. The dip of the foliation is steeply inclined toward the longitudinal axis and averages approximately $80^{\circ}$.

Below the right-angle bend, the foliation also has a general strike subparallel to the flow direction; however, the dips are uniformly toward Vaughan Lewis Glacier. These isoclinal dips reflect overturning caused by compression and overriding of the topographically higher wave bulges of Vaughan Lewis Glacier.

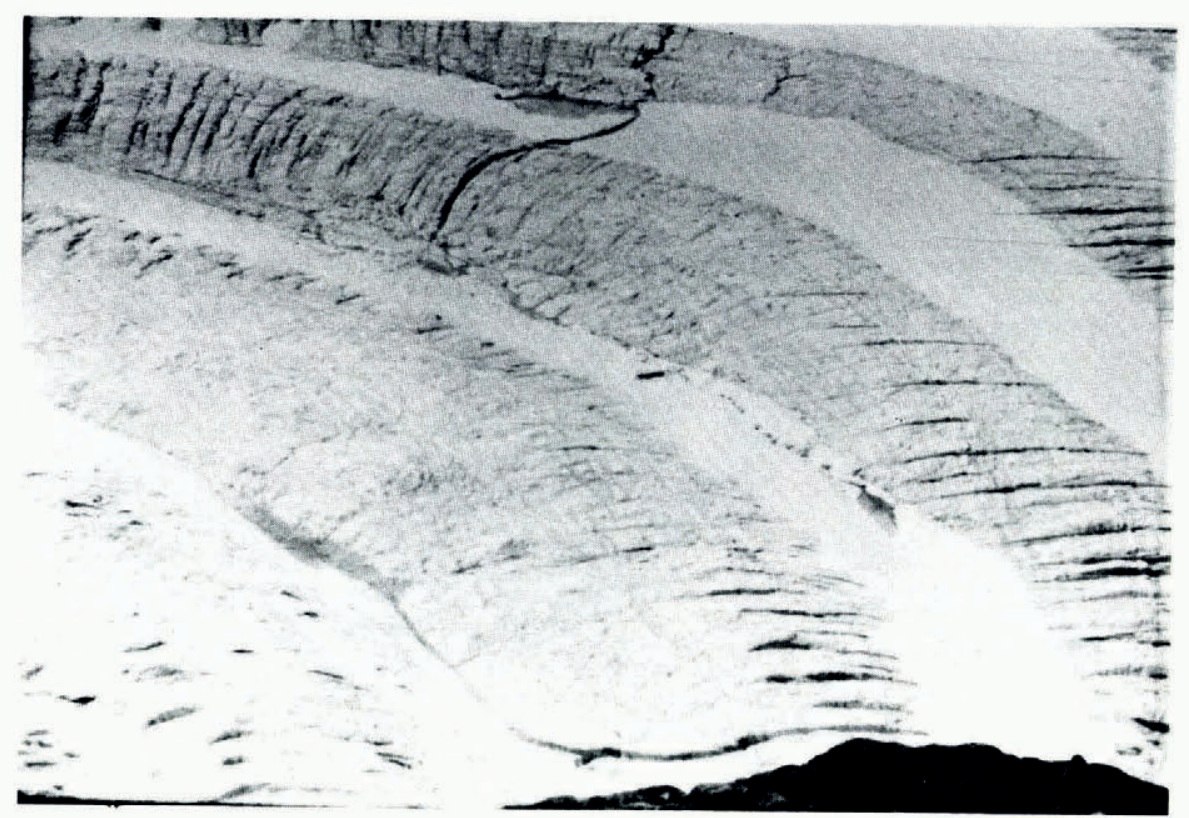

Fig. 4. Photograph of wave bulges of Vaughan Lewis Glacier. Note foliation and banding parallel to the arcs of the wave bulges, and the radial crevasses. Parallelogram patterns occur at the base of the firn in wave troughs.

Fractures within the ice are common. They are closely spaced and range from incipient cracks to crevasses $2 \mathrm{~m}$ wide. Many of the fractures are en echelon and extend only part-way across the glacier. Others are through-going and can be traced across the entire width of the Gilkey Trench. With few exceptions, in the areas of Gilkey Glacier where the parallelogram patterns occur, the fractures strike essentially perpendicularly to the foliation and the ice-flow direction and are interpreted as extension crevasses.

In interpreting the stress orientations, the englacial structures are recognized as strain manifestations and it is assumed that the principal strain-rates are parallel to the principal stresses. The most compressive stress is designated as $\sigma_{\mathrm{I}}$, the maximum principal stress. The least compressive or most tensile stress is designated as $\sigma_{3}$, the minimum principal stress.

The direction of lateral shortening or decrease in width of the glacier as indicated by the convergence of the moraines is, therefore, interpreted as $\sigma_{1} . \sigma_{\mathrm{I}}$ would, thus, be parallel to the 
strike of the extension crevasses, perpendicular to the strike of the foliation, and approximately perpendicular to the longitudinal axis of the glacier and ice-flow direction. The minimum principal stress, $\sigma_{3}$, is interpreted to be tensile, oriented perpendicular to the strike of the extension crevasses, parallel to the strike of the foliation, and approximately parallel to the longitudinal axis of the glacier and the ice-flow direction. The intermediate principal stress, $\sigma_{2}$, would be mutually perpendicular to $\sigma_{1}$ and $\sigma_{3}$, and normal to the surface of the glacier.

Englacial structures below Vaughan Lewis Icefall are more intensely developed than those in the ice of the glaciers of the Gilkey System, and bands and lenses of white bubbly ice are more abundant. Owing to greater velocities of the ice in the center of the glacier, the wave bulges at the base of the fall form smooth arcs convex down-stream. The foliations and white ice bands strike subparallel to the crests of the wave bulges and similarly form arcs convex in map view (Fig. 5).

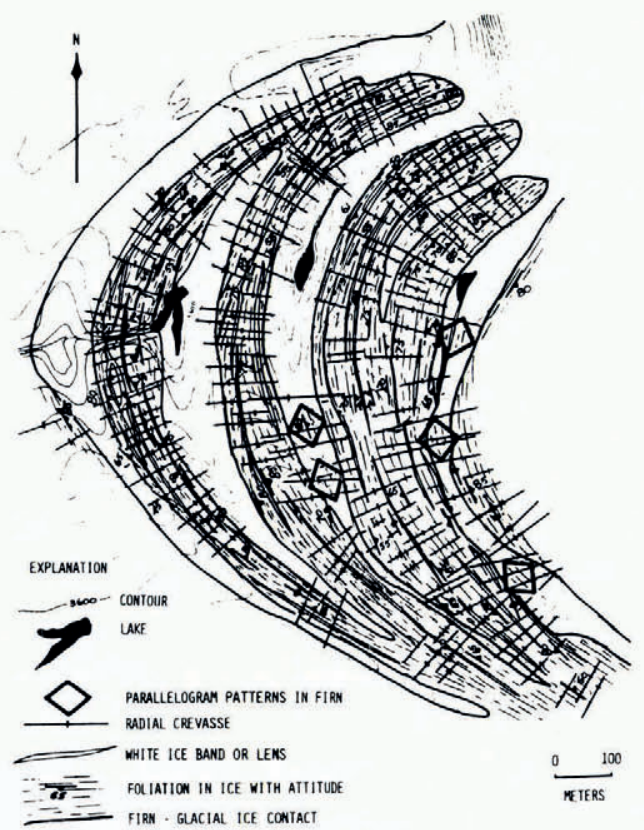

Fig. 5. Map of the structures in the wave bulges showing average orientation of patterns at various locations in the wave troughs. Angles are approximate.

Radial fractures ranging from incipient joints to broadly-open radial crevasses are abundant in the wave bulge zone. The strikes of the fractures are normal to the strikes of the foliations, and the fractures form a slightly asymmetric fan divergent down-glacier.

The stresses within the ice of the Vaughan Lewis wave bulges may be interpreted from the englacial structures. These interpreted stresses may then be analyzed relative to the parallelogram patterns which occur within the wave troughs.

The open radial crevasses indicate extension perpendicular to the strikes of the crevasses and parallel to the foliation and white bubbly ice bands in the arcs. The extension directions are interpreted as the least principal stress directions, or $\sigma_{3}$. Thus, $\sigma_{3}$ would be tensile and oriented perpendicular to the radial crevasses and parallel to the strikes of the foliation arcs. $\sigma_{1}$ as interpreted would be compressive, parallel to the strike of the radial crevasses, normal to the extension direction, and normal to the strikes of the foliation and the white ice bands. $\sigma_{2}$ would be mutually perpendicular to $\sigma_{1}$ and $\sigma_{3}$, and normal to the surface of the glacier. 
Since the extension crevasses (radial crevasses) form a fan opening down-glacier, the orientation of $\sigma_{1}$ must also form a fan divergent down-stream. Near the center of the glacier, $\sigma_{1}$ is oriented parallel to the main ice flow direction. Laterally, toward the moraines and along the arc of the foliation, $\sigma_{1}$ fans out coincident with the radial crevasses, and is oriented at larger and larger angles to the main ice-flow direction.

Upon initial inspection, the divergent $\sigma_{t}$ orientations in the Vaughan Lewis wave bulges may appear to be in contradiction with the previous analysis of the Ogilvie-Gilkey stress orientations where $\sigma_{1}$ was interpreted to be perpendicular to the main ice-flow direction. In the wave bulges, although the principal ice flow is down-glacier, local elongation along the arc of the foliation is evident. This local elongation is manifested as increased arc lengths with distance down glacier, and by the development of an abundance of radial fractures ranging from incipient rents to broadly open radial crevasses. Therefore, the orientations of the local stresses along the foliation arcs are indicated not by the main ice-flow direction, but by the local orientation of the foliation and the radial crevasses. Such differences between the direction of principal flow and the direction of local elongation is evident in the behavior of many viscous materials, e.g. pahochoe flows, and has been noted by Hans Cloos (1 925, p. 52, 53) in his discussion of the development of schlieren domes and arches of flow lines in plutons. In fact, the wave bulges of Vaughan Lewis Glacier are excellent geometric and kinematic models for the study of the development of schlieren domes, querklüfte (crossjoints), and other structures attendant to pluton emplacement (Waag, 1972).

\section{Orientations of THE REcrystallization parallelogram patterns}

To obtain quantitative information on the orientations of the rhombi and rhomboids, the strikes of the narrow zones of recrystallization outlining these parallelograms were measured using a pocket transit. Figure 6 presents rose diagrams and schematic rhombi which summarize the orientations of the sides of the parallelograms. The data plotted in the rose diagrams were gathered during the 1973 and 1974 field seasons at eight observation stations on Ogilvie-Gilkey Glacier and other glaciers of the Gilkey System, and at five stations within the troughs of the wave bulges of Vaughan Lewis Glacier (Fig. 5).

The schematic rhombi or diamonds in Figure 6 were generated by plotting the averages of the modes of the rose diagrams as the sides of the rhombi. The obtuse and acute angles of the diamonds in Figure 6 range from $95^{\circ}$ and $85^{\circ}$ to $115^{\circ}$ and $65^{\circ}$. The axial ratios of the diamonds range from I.I to $\mathrm{I} .57$.

As indicated in Figure 6, the parallelogram patterns on Ogilvie-Gilkey Glacier and the other glaciers of the Gilkey System were consistently oriented with the long axes of the rhombi and the acute-angle bisectors of the rhomboids subparallel to the foliation and to the ice-flow direction. Therefore, the long axes of the rhombi and the acute-angle bisectors of the rhomboids were consistently subparallel to $\sigma_{3}$. The short axes of the rhombi and the obtuse-angle bisectors of the rhomboids were subparallel to the extension crevasses; thus, subparallel to $\sigma_{t}$. The term subparallel is used here because for the data from glaciers of the Gilkey System the long axes of the patterns are rotated an average of $8^{\circ}$ clockwise from the down-glacier direction. Possible causes of this consistent rotation will be discussed later.

The parallelogram patterns in the troughs of the wave-bulges were also oriented consistently relative to the interpreted stress orientations, as shown in Figures 5 and 6 . The long axes of the rhombi and the acute-angle bisectors of the rhomboids were oriented parallel to the foliation or local extension direction, thus parallel to $\sigma_{3}$. The short axes of the rhombi and the obtuse-angle bisectors of the rhomboids were oriented parallel to the radial crevasses, thus parallel to $\sigma_{1}$. It is considered significant that these orientations are maintained even as the strikes of the radial crevasses diverge from parallel to the principal ice-flow direction in the center of the foliation arc to angles greater than $40^{\circ}$ where the arcs terminate against the moraines (Fig. 5). 


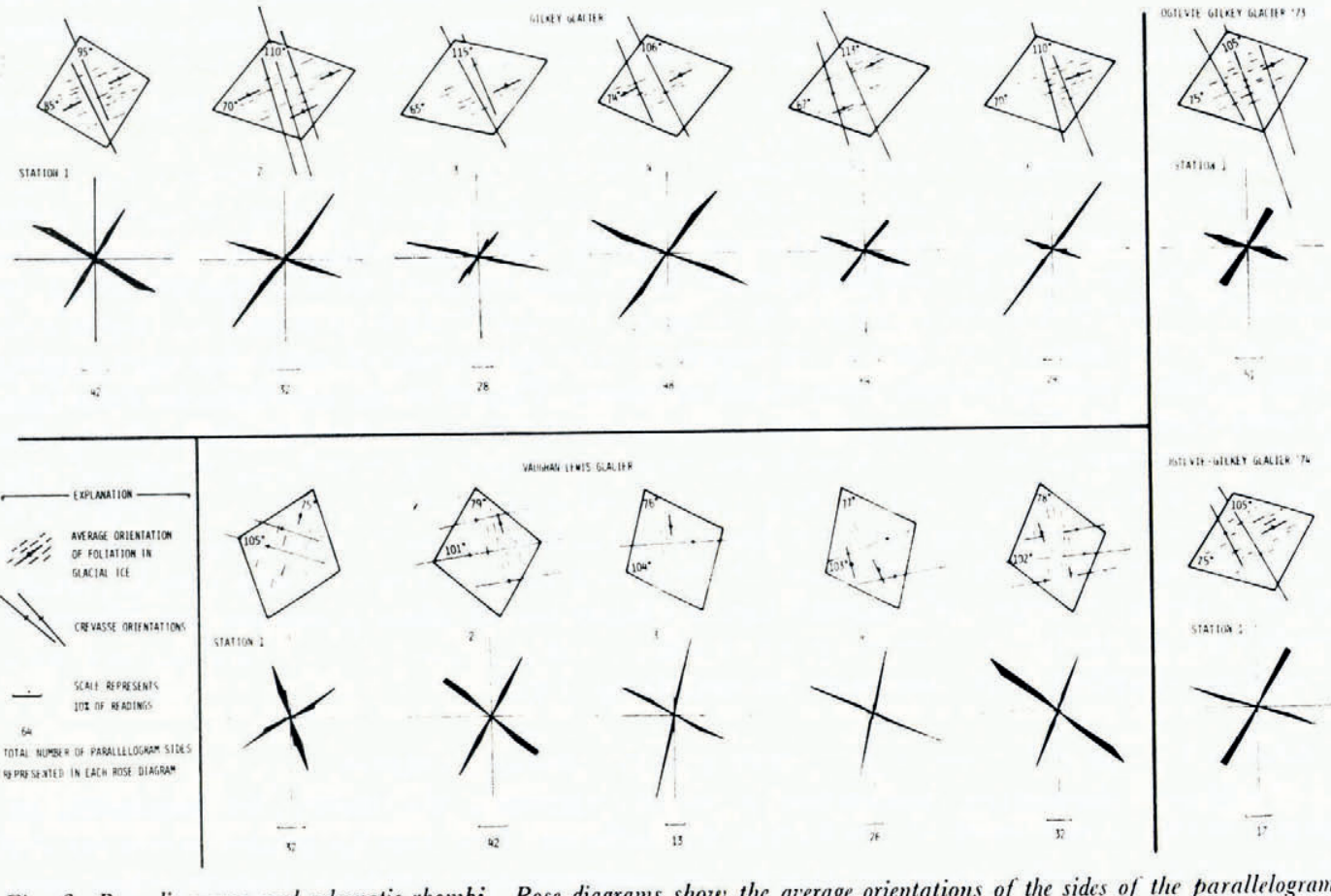

Fig. 6. Rose diagrams and schematic rhombi. Rose diagrams show the average orientations of the sides of the parallelogram patterns at various stations $1,2,3$, etc., on the glaciers. The schematic rhombi reflect the average angles and axial orientations of the patterns shown with the local crevasses and ice foliation orientations.

It is this consistent relationship between the orientations of the parallelograms and the orientations of the englacial structures and their interpreted stress directions which prompts the interpretation that the recrystallization patterns are natural strain indicators of the stresses within the ice. It follows, however, that if the patterns are indeed strain manifestations, not only are their orientations significant, but the axial ratios of the rhombi may somehow reflect the relative magnitudes of the strains. That is, if the orientations of the strains are indicated by the orientations of the axes of the rhombi, are the lengths of the axes somehow related to the strain-rate magnitudes? Since the obtuse and acute angles of a rhombus vary with the axial ratio, does the $20^{\circ}$ range in angles as shown in Figure 6 reflect slightly different levels of strain within the ice? It is interesting to note that those data gathered at the same location on Ogilvie-Gilkey Glacier during both the summer of 1973 and the summer of 1974 yield similar rose diagrams and schematic diamonds with identical angles and orientations. If the patterns do reflect magnitude as well as orientation, then the data would indicate that the orientations and the levels of strain within the ice at that station were the same during those two observation years.

During the summer of 1973 the same firn patches on Ogilvie-Gilkey Glacier which contained the parallelogram patterns were buckled into a number of anticlines and synclines (Waag, 1974). Although the firn folds gave no indication of the magnitude of the stresses involved, the stress orientations interpreted from the physical setting and the structures within the ice were corroborated by the folds within the overlying firn patches. The trends of the firn fold axes were parallel to the strike of the foliation in the ice, and perpendicular to the strike of the extension crevasses. As would be expected, the firn fold axes were oreinted 
perpendicular to the direction of maximum shortening, $\sigma_{1}$, and parallel to the direction of extension, $\sigma_{3}$. Thus, the structures within the glacial ice and the folds in the firn indicated the same stress orientations.

\section{Determination of STRAin-Rates}

\section{Introduction}

To test the hypothesis that the parallelogram patterns reflect the orientations and, perhaps, the magnitudes of strain-rates within the ice, preliminary measurements were made during the summer of 1974. Ogilvie-Gilkey Glacier was chosen as the site for the study because it provided the best control. The rhombus and rhomboid patterns had been observed there during two consecutive summers, and in 1973 the patterns were found in firn that had been folded.

\section{Measurements}

The measurements of the strain-rates followed the procedures outlined by Nye (1959) with some modifications of the strain arrays. Two square arrays of wood stakes were established as shown in Figure 7. Both arrays were oriented with one diagonal down-glacier (AC and $\mathrm{Ac}$ ). The arrays were established using a plane table, a Brunton compass as an open-sight alidade, and a measuring tape. The large array was approximately $12.2 \mathrm{~m}$ on a side, and the small array was approximately $6.1 \mathrm{~m}$ on a side. All measurements were originally made with a roo ft tape then converted to units of the metric system.

The stakes were placed in holes drilled to a depth of $1.5 \mathrm{~m}$ using a $2.54 \mathrm{~cm}$ SIPRE auger. Measurement errors induced by high ablation-rates adjacent to the stakes were reduced by packing rocks and glacier ice around the stakes, and by plumbing the stakes for each measurement. To minimize taping crrors each dimension of the array was measured several times and an average obtained. The arrays were remeasured after eleven days and six values of deformation corresponding to the six stake intervals for each array were obtained.

\section{Reduction of data}

The four values corresponding to the sides of the square arrays were reduced to two, by averaging the opposite sides of the squares, i.e. $\frac{1}{2}(A B+C D)$ and $\frac{1}{2}(A D+C B)$. The deformation intervals were then redesignated to correspond to the four directions $\theta=0^{\circ}, 45^{\circ}, 90^{\circ}$, and

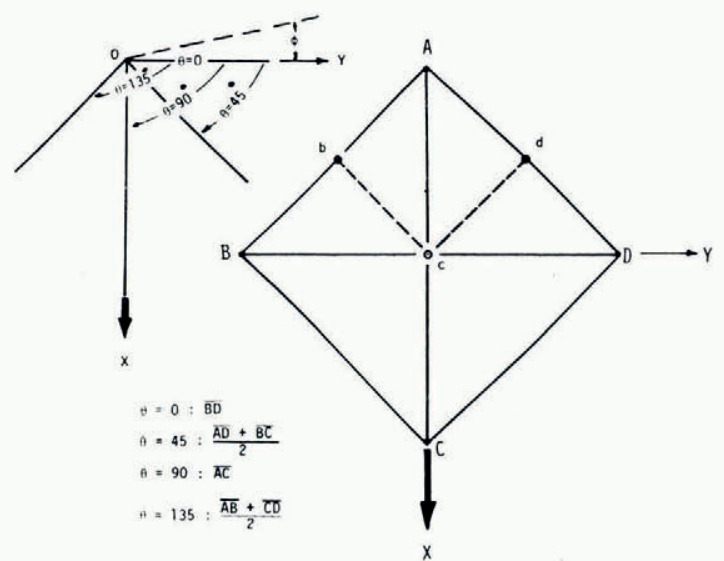

Fig. 7. Plot of the strain arravs showing the measured stake intervals and angles $\theta$ and $\phi$. Angles of $\theta$ correspond to the angular directions of the measured intervals in the sense shown. Angles of $\phi$ are between the $y$-axis and the nearest principal strain-rate
axes as shown. 
$135^{\circ}$, where $\theta$ is measured clockwise from $\mathrm{O} y$. The origin is at the center of the array, the $y$-axis is along BD and across glacier, and the $x$-axis is along the AC diagonal and downglacier. The $z$-axis is taken to $b$ : upward and normal to the glacier surface.

The average rates of stretching $\dot{\epsilon}$ of the intervals $\theta=0^{\circ}, 45^{\circ}, 90^{\circ}$, and $\mathrm{I} 35^{\circ}$ were determined using the relationship:

$$
\dot{\boldsymbol{\epsilon}}=\frac{\mathrm{I}}{\Delta t} \ln \frac{L_{2}}{L_{1}},
$$

where $L_{1}$ and $L_{2}$ are the initial and final lengths of a stake interval respectively, and $\Delta t$ is the time interval (Nye, 1959). Values of $\dot{\epsilon}$ are shown in Table I. A check of the data is provided by the relationship:

$$
\dot{\epsilon}_{0}+\dot{\epsilon}_{90}=\dot{\epsilon}_{45}+\dot{\epsilon}_{135} \text {. }
$$

Equation (2) holds if the variation in the strain-rate is linear within the area of the square. The values in Table I, column 8, may indicate that this is not actually the case for the ice within the area of the experiment, because the values $\left(\dot{\epsilon}_{0}+\dot{\epsilon}_{90}\right)-\left(\dot{\epsilon}_{45}+\dot{\epsilon}_{135}\right)$ are quite large. Possible explanations for this discrepancy will be discussed later.

Table I. The AVerage rate of Stretching of the measured intervals

(1)

Array Dates

Large 13 August-24 August

Small I3 August-24 August
(2)

(3)

(4)

(5)

(6)

(7)

In order that the angular strain-rates at the center of the square are represented by the angular subscripts, it is next assumed that the arrays were established as perfect squares. That this assumption is acceptable is indicated by a comparison between the dimensions of the test array and an ideal square. For the small array the difference between the dimensions of the actual and ideal squares ranged from $1.75 \%$ to $0 \%$ and average $0.57 \%$. The comparison for the large array is less favorable as the differences ranged from $1.75 \%$ to $0.125 \%$ and average $0.84 \%$.

From the four strain-rates $\dot{\epsilon}_{0}, \dot{\epsilon}_{45}, \dot{\epsilon}_{90}, \dot{\epsilon}_{135}$, the three tensor strain-rate components $\dot{\epsilon}_{x}, \dot{\epsilon}_{y}, \dot{\epsilon}_{x y}$, and their standard errors, were calculated using the least-squares procedure of Nye (1959) (Table II).

\begin{tabular}{|c|c|c|c|c|c|}
\hline Array & $\begin{array}{c}\dot{\boldsymbol{\epsilon}} x \\
\text { year }^{-1}\end{array}$ & $\begin{array}{c}\dot{\boldsymbol{\epsilon}}_{x y} \\
\text { year }^{-1}\end{array}$ & $\begin{array}{c}\dot{\boldsymbol{\epsilon}}_{y} \\
\text { year }^{-1}\end{array}$ & $\begin{array}{c}\text { Standard } \\
\text { error } \\
\dot{\epsilon}_{x} \text { and } \dot{\epsilon}_{y} \\
\text { year }^{-1}\end{array}$ & $\begin{array}{c}\text { Standard } \\
\text { error } \\
\dot{\boldsymbol{\epsilon}}_{x y} \\
\text { year }^{-1}\end{array}$ \\
\hline $\begin{array}{l}\text { Large } \\
\text { Small }\end{array}$ & $\begin{array}{r}+0.2569 \\
+0.1162\end{array}$ & $\begin{array}{l}-0.137 \mathrm{I} \\
-0.8358\end{array}$ & $\begin{array}{l}-0.6969 \\
-0.3437\end{array}$ & $\begin{array}{l}0.05^{8} \\
0.279\end{array}$ & $\begin{array}{l}0.047 \\
0.230\end{array}$ \\
\hline
\end{tabular}

TABle II. Strain-RAte components

The glacier is assumed to be a free surface, hence $\mathrm{O} z$ will be a principal axis of the stress tensor. Assuming that the principal axes of the stress tensor are parallel to the principal axes of the strain tensor, it follows that $\mathrm{O} z$ will be a principal direction of strain-rate, i.e. $\dot{\boldsymbol{\epsilon}}_{x z}=\dot{\epsilon}_{y z}=0$ and $\dot{\epsilon}_{z}=\dot{\epsilon}_{2}$.

Assuming that the ice is incompressible, the strain-rates will satisfy the relation $\dot{\epsilon}_{x}+\dot{\epsilon}_{y}+\dot{\epsilon}_{z}=0$. It follows that $\dot{\epsilon}_{2}=\dot{\epsilon}_{z}$ and then

$$
\dot{\xi}_{2}=-\left(\dot{\epsilon}_{x}+\dot{\epsilon}_{y}\right) \text {. }
$$


The magnitudes of the principal strain-rates $\dot{\epsilon}_{1}$ and $\dot{\epsilon}_{3}$ in the plane of the glacier surface $x y$ are given by the usual equations:

$$
\begin{aligned}
& \dot{\boldsymbol{\epsilon}}_{\mathrm{I}}=\frac{1}{2}\left(\dot{\boldsymbol{\epsilon}}_{x}+\dot{\boldsymbol{\epsilon}}_{y}\right)-\left[\frac{1}{4}\left(\dot{\boldsymbol{\epsilon}}_{x}-\dot{\boldsymbol{\epsilon}}_{y}\right)^{2}+\dot{\boldsymbol{\epsilon}}_{x} y^{2}\right]^{\frac{1}{2}}, \\
& \dot{\boldsymbol{\epsilon}}_{3}=\frac{1}{2}\left(\dot{\boldsymbol{\epsilon}}_{x}+\dot{\boldsymbol{\epsilon}}_{y}\right)+\left[\frac{1}{4}\left(\dot{\boldsymbol{\epsilon}}_{x}-\dot{\boldsymbol{\epsilon}}_{y}\right)^{2}+\dot{\boldsymbol{\epsilon}}_{x y} y^{2}\right]^{\frac{1}{2}} .
\end{aligned}
$$

The directions of the principal strain-rates $\dot{\epsilon}_{1}$ and $\dot{\epsilon}_{3}$ are given by

$$
\tan 2 \phi=\frac{2 \dot{\epsilon}_{x y}}{\dot{\epsilon}_{x}-\dot{\epsilon}_{y}},
$$

where $\phi$ is the angle between $\mathrm{O} y$ and one of the principal axes $\dot{\epsilon}_{\mathrm{I}}$ or $\dot{\epsilon}_{3}$ and in the sense shown in Figure 8. The values of the magnitudes and directions of the principal strains for both arrays are shown in Table III.

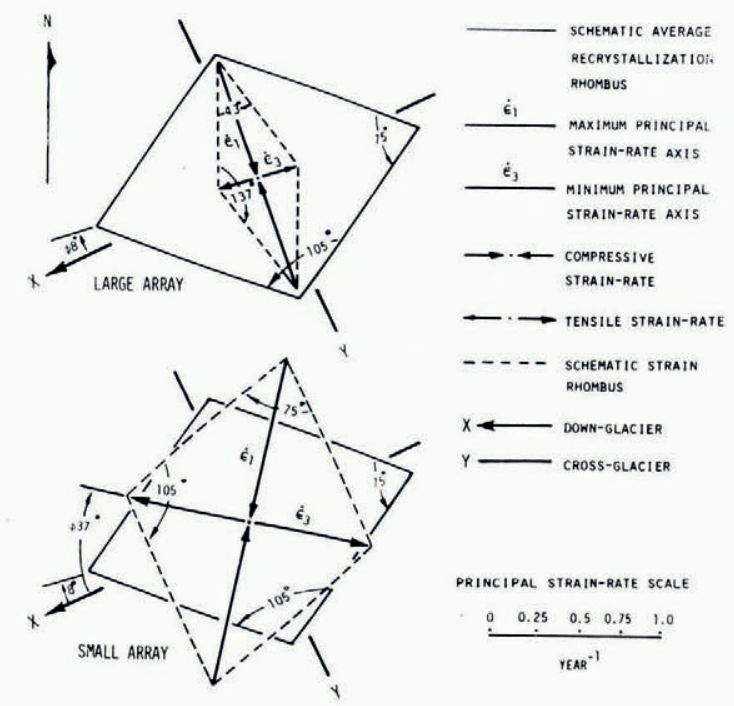

Fig. 8. a. Large array. b. Small array. Principal strain-rate axes plotted as rhombi and in relation to the average recrystallization rhombi from stations on Ogilvie-Gilkey Glacier. Note correspondence in orientation of axes for the large array and in angles (magnilude) for the small array.

Table III. Principal strain-kates And stresses

(1)

Array
Large
Small

Array

Large

Small

$$
\tau / \dot{e}
$$

(2)

$$
\underset{\text { year }^{-1}}{\dot{\boldsymbol{\epsilon}}_{\mathrm{I}}}
$$$$
-0.716
$$$$
-0.98 \mathrm{I}
$$
bar year

$$
\text { 1. } 98
$$$$
\text { 1. } 56
$$

$$
\begin{gathered}
\text { (9) } \\
\sigma_{1}^{\prime} \\
\text { bar }
\end{gathered}
$$

(3)

$$
\begin{gathered}
\dot{\epsilon}_{2} \\
\text { year }^{-1}
\end{gathered}
$$

$$
\dot{\text { year }}^{-1}
$$$$
+0.44^{\circ}
$$$$
+0.276
$$$$
+0.227
$$$$
+0.753
$$

(4)

\section{(10)}

$\sigma_{2}^{\prime}$$$
-1.4^{2}
$$$$
\begin{array}{r}
-1.42 \\
-1.53
\end{array}
$$

bar
+0.87

+0.87
+0.35

$$
\begin{gathered}
\phi \\
\operatorname{deg} \\
-8 \\
-37
\end{gathered}
$$

(I I)

$\sigma_{3}^{\prime}$
bar

$+0.55$
(5)

Standard

$\Delta \phi$
$\operatorname{deg}$
\pm 2.4
\pm 7

(I2)

$\sigma_{1}$

bar

-2.29
$-\quad .88$
(6)

(7)

\begin{tabular}{cc}
$\dot{e}$ & \multicolumn{1}{c}{} \\
year $^{-1}$ & bar
\end{tabular}

1.24

$(13)$

(13) (14)

$\begin{array}{cc}\sigma_{3} & \sigma \\ \text { bar } & \text { bar }\end{array}$

$-0.33-0.87$ 


\section{Calculation of stresses}

Assuming that at any point the strain-rates are parallel and proportional to the corresponding stress deviators, the stress conditions at the center of each array may be calculated from the principal strain-rates. The hydrostatic stress is defined by:

$$
\sigma=\frac{1}{3}\left(\sigma_{1}+\sigma_{2}+\sigma_{3}\right) \text {. . }
$$

The stress deviators are designated $\sigma_{i}{ }^{\prime}$ where $i=1,2,3$ and are defined by:

$$
\sigma_{1}{ }^{\prime}=\sigma_{1}-\sigma, \quad \sigma_{2}{ }^{\prime}=\sigma_{2}-\sigma, \quad \sigma_{3}{ }^{\prime}=\sigma_{3}-\sigma .
$$

The effective strain-rate $\dot{e}$ and the effective shear stress $\tau$ are defined by Nye (1953) as:

$$
2 \dot{e}^{2}=\dot{\epsilon}_{1}^{2}+\dot{\epsilon}_{2}^{2}+\dot{\epsilon}_{3}^{2},
$$

and

$$
2 \tau^{2}=\sigma_{1}{ }^{2}+\sigma_{2}{ }^{2}+\sigma_{3}{ }^{2} .
$$

Assuming a flow law of the form $\dot{e}=f(\tau)$ exists, Nye (1957) has shown that the stress deviators have the following relationship:

$$
\sigma_{1}{ }^{\prime}=\frac{\tau}{\dot{e}} \dot{\epsilon}_{1}, \quad \sigma_{2}{ }^{\prime}=\frac{\tau}{\dot{e}} \dot{\epsilon}_{2}, \quad \sigma_{3}{ }^{\prime}=\frac{\tau}{\dot{e}} \dot{\epsilon}_{3} .
$$

Using the flow law developed by Glen (1955) $\dot{e}=A \tau^{n}$, if $\dot{e}$ is in year-1, $\tau$ is in bars and $A$ and $n$ have the values derived by Nye (1953) of 0.33 year $^{-1}$ and 3.0 respectively then

$$
\tau=1.44^{\dot{e} 0.33} \text {. }
$$

The effective strain-rate $\dot{e}$ is calculated using Equation (9) and then $\tau$ from Equation (12). $\sigma_{1}^{\prime}, \sigma_{2}{ }^{\prime}$ and $\sigma_{3}{ }^{\prime}$ are determined using Equation (1 $\mathrm{I}$ ).

Neglecting atmospheric pressure $\left(\sigma_{2}=0\right)$, then

$$
\sigma=\frac{1}{3}\left(\sigma_{1}+\sigma_{3}\right)
$$

and

$$
\begin{aligned}
& \sigma_{1}=2 \sigma_{1}{ }^{\prime}+\sigma_{3}{ }^{\prime}, \\
& \sigma_{3}=\sigma_{1}{ }^{\prime}+2 \sigma_{3}{ }^{\prime} .
\end{aligned}
$$

Table III presents the calculated values of $\dot{e}, \tau$, the stress deviators, $\sigma_{1}$, and $\sigma_{3}$.

CORRELATION OF THE STRESS AND STRAIN FIELDS WITH THE RECRYSTALliZATION PATTERNS, THE ICE AND FIRN STRUGTURES, AND THE PHYSICAL SETTING

Using the calculated values, a semi-quantitative look at the recrystallization patterns may be obtained. Figure 8 shows the greatest and least principal strain-rates from the stake arrays plotted in relation to the average recrystallization rhombi. For ease of comparison, the magnitudes and the orientations of the principal strain-rates are also plotted as the major and minor axes of rhombi. In Figure 8a, the large array, $\dot{\epsilon}_{\mathrm{I}}$ is within one degree of being parallel to the average short axis of the recrystallization rhombus. Similarly, $\dot{\epsilon}_{3}$ is within one degree of being parallel to the long axis of the recrystallization rhombus. Since the principal axes of the stress tensor are taken to be parallel to the principal axes of the strain-rate tensor, $\sigma_{1}$ and $\sigma_{3}$ will also be parallel to the axes of the recrystallization rhombus. It will be noted in Figure 8a, however, that although the three sets of axes are parallel they are all rotated $8^{\circ}$ clockwise with respect to the mean down-glacier and cross-glacier directions, $x$ and $y$ respectively.

An angular difference between the axes of the recrystallization patterns and the glacier directions became evident early in the study. Data gathered from orientations of the recrystallization patterns on Ogilvie-Gilkey Glacier in both 1973 and 1974 indicated that the long axes of the average recrystallization rhombi were skewed $7^{\circ}$ to $8^{\circ}$ clockwise from the down-glacier 
direction. Two possible sources of shear to cause this clockwise rotation are evident in the physical setting. The patterns were observed immediately below the right-angle clockwise bend in the glacier. The rotation of the parallelogram patterns may be induced by effects in the ice as it is forced through the bend. A second possibility is that the clockwise skewing of the parallelogram patterns results from differences in the velocities of the glaciers flanking Ogilvie Gilkey Glacier. Vaughan Lewis Glacier, adjacent on the south, is a relatively fastflowing glacier. Theodolite measurements of surface movements at the base of the ice fall yield average velocities of $2 \mathrm{ft}^{-1}\left(0.6 \mathrm{~m} \mathrm{~d}^{-1}\right)$. Reliable velocity measurements are not available for the glaciers of the Gilkey System on the north; however, judging from the physical setting it is probable that the velocities are less than those of Vaughan Lewis Glacier. If this is the case, the faster-flowing Vaughan Lewis Glacier would effect a clockwise rotation of the stress and strain fields in the vicinity of the arravs.

During the period in which the deformation was being measured, a crevasse developed within the ice spanned by the small array. Unfortunately the movement and sounds were sufficiently startling and distracting that the sense of movement of the blocks could not be agreed upon. Many of the crevasse-bound blocks, however, do indicate a clockwise rotation. Significantly, both arrays recorded a clockwise rotation of the strain-rate axes from the downglacier and cross-glacier directions (Fig. 8). The greater rotation recorded by the small array may partly reflect the crevasse which formed during the experiment. Since the directions of the principal strain-rates $\dot{\epsilon}_{1}$ and $\dot{\epsilon}_{j}$ are given by Equation $(6)$, their orientations are affected by the relative magnitudes of the strains. The newly formed crevasse would be expected to introduce proportionately larger strain-rates in the small array (Table III).

Such crevasse development also violates the assumption that the variations in the strainrates within the areas of the squares are linear. That the data from the small array conform less well to the assumption is evident in Table I, column 8.

The signs and general magnitudes of $\sigma_{1}$ and $\dot{\epsilon}_{1}$ for the large array (Table III) are consistent with the earlier interpretations of $\sigma_{1}$ based upon the structures within the firn and ice. It was anticipated that $\dot{\epsilon}_{1}$ and $\sigma_{1}$ would be strongly compressive as indicated by the rapidly converging moraines, the abundant firn folds, and the cross-glacier crevasses. The calculated values of -0.716 year $^{-1}$ and -2.29 bar for $\dot{\epsilon}$ and $\sigma_{1}$ respectively reflect this strong cross-glacier compression.

The signs and magnitudes of $\dot{\epsilon}_{3}$ and $\sigma_{3}$ for the large array are not as supportive. $\dot{\epsilon}_{3}$ was tensile although the 0.276 year $^{-1}$ rate was weaker than anticipated. $\sigma_{3}$, by contrast, was unexpectedly compressive but quite weak at -0.33 bar compared to $\sigma_{1}$ at -2.29 bar. The change from a weakly tensile $\dot{\epsilon}_{3}$ to a weakly compressive $\sigma_{3}$ in this case results mainly from a relatively large confining pressure $\sigma$. The minimum principal stress deviator $\sigma_{3}^{\prime}$ was tensile; however, $\sigma$ was comparatively large and Equation 8 yields a weakly compressive $\sigma_{3}$ for the large array.

For the small array $\dot{\epsilon}_{1}$ and $\sigma_{1}$ are strongly compressive, and $\dot{\epsilon}_{3}$ and $\sigma_{3}$ are moderately to strongly tensile. These conditions are quite consistent with the rapidly converging moraines, the firn folds, and the abundance of open cross-glacier crevasses.

Earlier, it was suggested that even though the mechanisms of formation of the recrstallization patterns are not understood, the geometry of the patterns might somelow reflect the magnitudes of the strain-rates within the ice. The magnitudes of the principal strain-rates for the small array are especially interesting when considered in this context. The average recrystallization rhombi observed during the 1973 and $197+$ seasons on Ogilvie Gilkey Glacier had angles of 75 and 105 and axial ratios of 1.3 (Figs 6 and 8). (Curiously, a plot of the values of $\dot{\epsilon}_{1}$ and $\dot{\epsilon}_{3}$ from the small array (Fig. (b) vields a rhombus having the same axial ratio and angles. The magnitudes of the principal strain-rates from the large array are not as supportive. A rhombus plotted using $\dot{\epsilon}_{1}$ and $\dot{\epsilon}_{;}$as axes has angles of 43 and 1,37 and an axial ratio of 2.59 (Fig. 8a). A summary of axial ratios is presented in Table IV. 
Table IV. Axial ratios Ogilvie-Gilkey Glacier

$\begin{array}{rcccc}\text { Array } & \dot{\epsilon}_{1}: \dot{\epsilon}_{3} & \sigma_{1}{ }^{\prime}: \sigma_{3}{ }^{\prime} & \sigma_{1}: \sigma_{3} & \begin{array}{c}\text { Aierage of } \\ \text { pattirns }\end{array} \\ \text { Large } & 2.59 & 2.58 & 6.9 & \\ \text { Small } & 1.3 & 1.3 & 2.29 & 1 \cdot 3\end{array}$

In summary, the calculated principal strain-rates and stress tensors seem generally to support the hypothesis that the firn recrystallization patterns do reflect the stress and strain fields within the underlying glacial ice. The data are preliminary, however, and not unequivocal. Although the principal strain-rate axes determined for the large array have essentially the same orientations as the axes of the recrystallization patterns, the magnitudes of $\dot{\epsilon}_{\mathrm{I}}$ and $\dot{\epsilon}_{3}$ determined from the small array correlate better with the axial ratios of the average recrystallization rhombi.

The signs of the principal axes of the strain-rate and stress tensors for both arrays correlate well with the physical setting and the structures within the ice and firn. $\dot{\epsilon}_{1}$ was compressive and $\dot{\epsilon}_{3}$ was tensile for both arrays. For the small array $\sigma_{1}$ was compressive and $\sigma_{3}$ was tensile. For the large array $\sigma_{1}$ was also strongly compressive; however, $\sigma_{3}$ was weakly compressive. Although this weakly compressive $\dot{\sigma}_{3}$ contrasts with the rather strongly tensile $\sigma_{3}$ indicated by the small array, such differences are not uncommon in glaciers.

Differences in sign and magnitude in the strain and stress fields at points in close proximity on glaciers have also been observed by Nye (1959, p. 410) and Colbeck and Evans (1969, p. 10). On Blue Glacier, Mount Olympus, Washington, Colbeck and Evans (I969, p. 1 2) recorded an abrupt increase in strain-rate between adjacent stakes spanning a newly formed crevasse. They also noted reversals of strain between other sets of stakes close to but not spanning a newly formed fracture. Colbeck and Evans suggested that the fracture may have led to a redistribution of stress that resulted in a change in the direction of strain-rate. The weakly compressive $\sigma_{3}$ recorded by the large array on Ogilvie-Gilkey Glacier is here interpreted as reflecting a similar stress redistribution attendant to the development of the crevasse within the small array. It seems unlikely that the parallelogram patterns observed in the firn would have sufficient time to undergo significant recrystallization in response to such temporary and relatively minor redistributions of stress. Rather, the patterns probably integrate such changes along with the longer-term stress conditions to which the ice and firn are exposed as they move down-glacier.

\section{Conclusions}

The orientations of the parallelogram patterns in the firn are indeed closely related to the orientations of the principal directions of the strain field in the underlying ice. The axial ratios and internal geometry of the patterns also appear to be linked quantitatively to at least the intermediate or longer-term average magnitudes of the strain field. The evidence that the geometry of the patterns reflects the magnitude of the strain is less compelling, however, than that which indicates a similarity of orientation between the strain field and the patterns.

These conclusions, although tentative, focus attention upon questions concerning the precise origin of the patterns. What are the mechanisms of propagation of the strains from the glacial ice into the overlying firn, and what factors control the size of the patterns? What is the range of recrystallization rates in the firn, and how are the rates related to changes in stress conditions? What are the orientations of the firn crystals? Are they, as suspected, preferred? If so, how is the preferred firn-crystal orientation related to the patterns? How responsive to 
changes in stress conditions during down-glacier movement are already established parallelogram patterns? Are the patterns present in the ice as well as the firn? If the parallelogram patterns are present in the glacial ice, do they have any relationship to already identified quadrimodal $c$-axis orientations found in glacial ice by others?

More definitive studies of the patterns including petrofabric analyses of the firn and ice, and more precise strain-rate measurements are planned to answer these and other pertinent questions.

\section{Acknowledgements}

The observations and measurements contained in this paper were made as part of the $14^{\text {th }}$ and ${ }_{1} 5^{\text {th }}$ Summer Institutes of Glaciological and Arctic Sciences, Juneau Icefield, Alaska. The Institutes were partially supported by the National Science Foundation, the Foundation for Glacier and Environmental Research, the Juneau Icefield Research Program, and the Army Research Office. The writers are grateful to many of the participants of the institutes for their assistance in the field, and especially indebted to Dr Maynard M. Miller, the Institute director.

MS. received 19 June 1.978 and in revised form 9 October 1.978

\section{REFERENCES}

Cloos, H. 1925. Einführung in die tektonische Behandlung magmatischer Erscheinungen. 1. Das Riesengebirge in Schlesien. Berlin, Gebr. Borntraeger.

Colbeck, S. C., and Evans, R. J. 1969. Experimental studies related to the mechanics of glacier flow. Trend in Engineering at the Unizersity of Washington, Vol. 21, No. 2, p. 8-14.

Glen, J. W: 1955. The creep of polycrystalline ice. Proceedings of the Royal Society of London, Ser. A, Vol. 228, No. 1175 , p. 519-38.

Kamb, W. B. 1959. Ice petrofabric observations from Blue Glacier, Washington, in relation to theory and experiment. Journal of Geophysical Research, Vol. 64, No. 11, p. 1891-909.

Nye, J. F. 1953. The flow law of ice from measurements in glacier tunncls, laboratory experiments, and the Jungfraufirn borehole experiment. Proceedings of the Roval Society of London, Ser. A, Vol. 219, No. 1 1 39, P. 47789.

Nye, J. F. 1957. The distribution of stress and velocity in glaciers and ice-sheets. Proceedings of the Royal Society of London, Ser. A, Vol. 239, No. 1216, p. $113-33$. Nye, J. F. 1959. A method of determining the strain-rate tensor at the surface of a glacier. Journal of Glaciolog),
Vol. 3, No. 25, p. $409-19$. Rigsby, G. P. 1951. Crystal fabric studies on Emmons Glacier, Mount Rainier, Washington. Journal of (ieolog),
Vol. 59, No. 6, p. $590-98$.

Waag, C. J. 1972. Glaciers as structural models. Geological Society of America. Abstracts with Programs, Vol. 4, No. 3 , p. 254 .

Waag, C. J. 1974. Firn folds, a model for cover rock deformation attendant to basement shortening. Geological Society of America. Abstracts with Programs, Vol. 6, No. 4, p. 409 .

Waag, C. J. I 975 . Rhombus and rhomboid parallelogram patterns on glaciers as natural strain indicators. Geological Society of America. Abstracts with Programs, Vol. 7, No. 3, p. 383 . 